\section{Simplification of Musical Notation}

THE value of the scientific method, to which Lord Brabazon appeals, lies in the proper use of experiment. There is available to-day a growing amount of piano music which is written without key signature, because it is without key, and with chromatic notes inserted as required. It is easy to find out whether it has the advantages Lord Brabazon assumes for his tentative proposal to omit key signatures as a first step towards a simpler notation.

For my own part I find this music difficult to read, because I have then to read each note. That may be one reason why such music repels me. But for earlier music, for which staff notation was developed, Lord Brabazon's analogy with the printed book is a good one. Just as one does not read each letter, perhaps not even each word, of a printed sentence (whence the difficulty of proof correction), so in reading music one has no time to read each note. One reads groups of notes.

Such proposed alternatives for staff notation as I have seen do not readily assist this kind of reading. In other words, they hold no promise of standing up to the scientific test, that of the control experiment. Until someone invents a notation that does, which will make music in twelve-tone technique easier to read, and perhaps to understand, musicians will remain hopeful but not expectant.

\section{Department of Scientific and}

Industrial Research,

Teddington, Middlesex.

The plea of Lord Brabazon in NATURE of May 16, p. 554, will be strongly supported by thousands of would-be players to whom the complications of clefs, key changes and accidentals have proved an impassable barrier, and by the parents of many otherwise musical children who have given up their pianoforte studies in despair because of these difficulties. On the plea of the greatest good for the greatest number, therefore, Lord Brabazon's appeal ought to receive most careful and unbiased consideration, and not least from those musicians whose real desire it is to extend the art of music-making among ordinary people. Furthermore, the use of a special form of stave for the piano and organ would not be so great a departure from tradition as might at first be supposed, for is it not on a par with the provision of special clefs for some of the instruments in the orchestra? (Incidentally, why must we continue to use an $H$ to denote a $C$ clef, and a $C$ for an $F$ clef ?)

As a practical contribution may I put forward a simple solution ? Why not make the appearance of the printed music bear an easily recognized resemblance to the array of black and white keys on the keyboard ? Thus: make the stave consist of horizontal lines in sets of twos and threes, so that the black lines correspond to the black keys, and the white spaces the white keys. This would do away with the "treble" and "bass" clefs, with their different names for similarly placed symbols, and eliminate all sharps and flats. The three octaves at present included within the compass of the normal treble and bass clefs would naturally occupy a little more space, but the gain in clarity is obvious, every note on the keyboard having its unmistakable and unique position on the printed page.

The following example shows the first six bars of the National Anthem in the key of $A$ (3 sharps) written in the new notation*. The 'dot' forming the commencement of the " $C$ " at the beginning of the stave represents the middle $C$ of the piano.

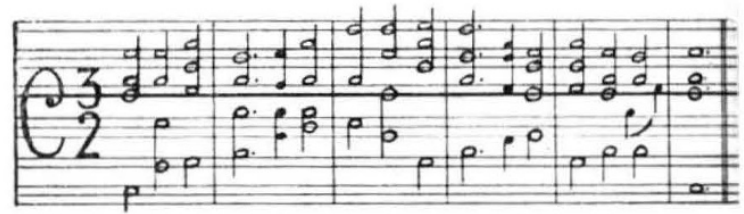

The line denoting middle C sharp is purposely made bolder; this guides the eye and improves clarity.

Leger lines, with similar gaps between the groups of twos and threes, would be employed for notes above and below the stave, but the use of the (8ve) and (16ve) devices is to be strongly recommended wherever possible.

If any music publisher should be sufficiently interested and large-minded to answer Lord Brabazon's plea by preparing to issue a series of graded classical and popular music in some such simplified notation, as soon as war-time restrictions are relaxed, he would earn the gratitude of many now living who are debarred from 'making their own music' by the barbed-wire entanglements of sharps and flats, and would bring into the realm of possibility for future generations an era of 'music without tears'.

KENNETH B. WoOD (formerly Musical Director, Southfields Central Hall, S.W.)

135 Sunny Gardens Road, Hendon, N.W.4.

* Since devising this stave I have found that one on similar lines was put forward some 50 or 60 years ago by Mitcherd. Evidently then the times were not propitious!

\section{Luminous Phenomenon Accompanying the Cyprus Earthquake, January 20, 1941}

As reported in Nature of February 1 and 8, 1941, an earthquake of intensity VII or VIII on the ForelMercalli scale-the severest in Cyprus for the last sixty years-occurred on January 20, 1941, at about 5.35 local time. The beginning, as recorded at Ksara Observatory near Beyrouth, was 3h. 37m. 38s. G.M.T.

The epicentre lies between Cyprus and the Syrian coast, $200 \mathrm{~km}$. from the latter and probably near the south-east coast of Cyprus. This is a region where earthquakes are not very rare.

A bright flash associated with the earthquake was seen from the eastern and central parts of the island. A Nicosia Hodja who was on the minaret for morning prayer, in describing the event, said that he first heard a deafening noise suggesting the impact of a gigantic projectile on the surface of the earth with a simultaneous rocking motion so severe that he feared the minaret would collapse. Afterwards he saw a brilliant reddish object like a huge globular lightning moving slowly towards the east. The tremors then changed into horizontal waves and gradually vanished. There is strong evidence that direction of the flash was pointing to the epicentral area.

Abdulazim Aziz.

Department of Agriculture, Nicosia, Cyprus. 